\title{
Personality and Performance in Eventing
}

\author{
Jennifer Hart ${ }^{1}$, Adrian Furnham ${ }^{1,2}$ \\ ${ }^{1}$ Research Department of Clinical, Educational and Health Psychology, University College London, London, England \\ ${ }^{2}$ Norwegian Business School (BI), Olso, Norway \\ Email: a.furnham@ucl.ac.uk
}

How to cite this paper: Hart, J., \& Furnham, A. (2016). Personality and Performance in Eventing. Psychology, 7, 12671275 .

http://dx.doi.org/10.4236/psych.2016.710129

Received: August 2, 2016

Accepted: September 2, 2016

Published: September 5, 2016

Copyright $\odot 2016$ by authors and Scientific Research Publishing Inc. This work is licensed under the Creative Commons Attribution International License (CC BY 4.0).

http://creativecommons.org/licenses/by/4.0/

\section{Abstract}

This study examined the effects of personality on performance in the sport of Eventing. A questionnaire consisting of the abbreviated Big Five and Core-Self Evaluations (CSE) was administered to 155 participants who were split into three groups: Amateurs $(n=48)$, Progressive Amateurs $(n=62)$ and Professionals $(n=45)$. The criteria were self and other rated performance. The results showed that CSE, Conscientiousness and Extraversion were significant predictors of actual and rated performance. Implications and limitations were discussed.

\section{Keywords}

Big Five Personality, Core Self-Evaluations, Equestrian Eventing, Amateurs, Professionals

\section{Introduction}

This study looks at personality correlates of equestrianism, a sport which has largely been neglected in psychological research. It is a sport where men and women compete on equal terms and amateurs can compete against top professionals (British Eventing, 2009). Eventing is an equestrian triathlon with three disciplines: Dressage, Showjumping and Cross-country, each requiring different skills from the rider. It involves the partnership between horse and rider.

Eventing competitions are run under the organising body of British Eventing (BE) which runs six core national classes: BE80, BE90, BE100, Novice, Intermediate and Advanced as well as three progressive levels to help competitors move up to the next level. International classes are also run, ranging from one-star level (the equivalent of a hard Novice class) to four-star level (equivalent of a hard Advanced class).

This study examines personality correlates of success in Eventing. Two measures that look at different aspects of personality will be used in this study: the Five-Factor Model 
of Personality and Core-self evaluations.

\subsection{The Big Five}

Neuroticism is the tendency for a person to experience unpleasant emotions easily. Individuals who score highly are more prone to becoming anxious, worried, stressed and angry. Previous research has found that athletes, especially high performing athletes, tend to have a lower Neuroticism score, and they therefore suffer less from anxiety (Eysenck, Nias, \& Cox, 1982). Self-confidence is associated with low Neuroticism and has been found to positively correlate with performance (Taylor, 1987). Elevated anxiety levels are a cause of poor performance in most sports (LeUnes \& Nation, 1989; Dowd \& Inne, 1981). Eysenck et al. (1982), however, proposed that anxiety can act as a drive and therefore improve performance. Optimum anxiety is required: too low and motivation will be poor, but too high it will act as a distraction. However, the optimum may vary depending on the activity. Mahoney and Avener (1977) also suggest that it is not the levels of anxiety that determine a successful performer but their ability to control their anxiety. They found that successful gymnasts were better able to control their anxiety when it was inappropriate for their performance. It is hypothesised that in this study low Neuroticism will predict high performance in Eventing (H1).

Extraversion is characterised by individuals who seek stimulation and are out-going, assertive and determined individuals who tend to feel positive emotions. A large body of research has agreed on a common finding that sportsmen are more likely to be extraverts than non-sportsmen (Davies, 1989; Eysenck et al., 1982; Furnham, 1990; Kerr \& Cox, 1991), due to their low arousal levels and so their need to sensation seeking and risk taking (Canton \& Mayor, 1994; Vestewig, 1977). Eysenck et al. (1982) suggest that danger, possibly encountered by risk-taking behaviour, increases arousal more than safe activities. Risk-taking plays a part in many sports but especially the cross-country phase of Eventing. However, there are also sports that require very different skills, such as shooting which does not require athletes to be active and impulsive. Thus the relationship of Extraversion to sports success depends on the sport.

Conscientious individuals are generally hard working and reliable (Barrick \& Mount, 1991). They are self-disciplined and organised, and they have a need for achievement but may be seen as perfectionists or workaholics. It is the strongest predictor of work success and motivation (Salgado, 1997; Biderman, Nguyen, \& Sebren, 2008). Highly conscientious individuals tend to be more motivated and so will exert larger amounts of effort into their practise and training. Peterson, Weber and Lonsdale (1970) found Olympic athletes had higher C manifest in perseverance. Ogilvie (1970) found the same result in swimmers and Bird (1970) with hockey players. It is hypothesised that high Conscientiousness will predict high performance in Eventing (H2).

Individuals who score highly on Agreeableness tend to get along with others and believe that others are generally good, honest and trustworthy. It could be more relevant in team, rather than individual sports. Being co-operative with your team would seem 
necessary for success, whereas in an individual sport it is unlikely it is related to success. One study found that Agreeableness was a predictor for exercise dependence symptoms (Hausenblas \& Giacobbi, 2004). Consequently Hausenblas and Giacobbi suggest their findings are down to disagreeable people satisfying their competitive nature by engaging in excessive exercise.

High scores on the factor of Openness to experience suggest that individuals are creative, imaginative and curious. In relation to sport, Diehm and Armatas (2004) found that scores on Openness were significantly higher for those involved in the high-risk sport of surfing in comparison to those who took part in the low-risk sport of golf. Zuckerman, Kuhlman, Joireman, Teta and Kraft (1993) found that out of the Big Five Openness was the most strongly correlated to sensation seeking, which could also be another factor causing the individuals to take part in high-risk sports.

\subsection{Core Self-Evaluations}

Core Self-Evaluation (CSE) is a broad personality trait that reflects an individual's beliefs of their capabilities, competence and a general sense that their life will turn out well. It consists of four factors: self-esteem, generalised self-efficacy, locus of control and emotional stability. Self-esteem (SE) refers to the way individuals place views and values on themselves (Harter, 1990). It comprises self-acceptance, self-liking and self-respect. Generalised Self Efficacy (GSE) is an individual's judgement or perception of their ability to perform in forthcoming situations (Bandura, 1982). Locus of control refers to generalised expectancies of outcomes: those with internal beliefs have control over their destiny, while those with external beliefs assume chance, fate and luck are primary causes of what happen to them. Emotional stability is essentially a measure of high Adjustment or low Neuroticism (proneness to anxiety, depression and worrying).

Previous research has found that CSE is related to higher levels of job satisfaction, better performance and higher motivation (Judge \& Hurst, 2007). Judge et al. (2003) suggested that performance is altered by the affect of CSE on motivation. Erez and Judge (2001) found support for their hypothesis that individuals who scored highly would be more likely to persist when they encountered setbacks, would also have stronger beliefs in their capabilities and that they could control the outcomes. Despite the majority of research on CSE being carried out within organisational psychology, Judge (2009) suggested that findings will generalise to other areas of psychology. It is predicted that high CSE will predict high performance in Eventing $(\mathrm{H} 3)$.

\section{Method}

\subsection{Participants}

155 participants took part in the experiment ( 21 males, 134 females), the mean age was $27.3(\mathrm{sd}=10.32)$. They were divided up into three groups: amateurs $(\mathrm{n}=48)$, progressive amateurs $(n=62)$ and professionals $(n=45)$. These groups were defined as: Amateurs-You do not make a living out of riding and mainly compete at BE100 and below but may do some novices; Progressive Amateurs-You do not make a living out of rid- 
ing but you aim, or do compete at novice consistently and above; Professionals-You make a living out of riding.

\subsection{Measures}

The questionnaire consisted of four sections:

Demographics - a range of demographic questions were asked as well as questions about the participant's riding.

Abbreviated Big Five (McManus, Smithers, Partridge, Keeling, \& Fleming, 2003). This 15-item questionnaire measures: Openness, Conscientiousness, Extraversion, Agreeableness and Neuroticism. It has acceptable internal reliability and validity.

Core Self Evaluation Scale: (CSES: Judge, Erez, Bono, \& Thoresen, 2003). The 12 -item scale measures the four traits of self-esteem, generalised self-efficacy, locus of control and emotional stability.

Eventing Performance: To measure the performance of the participant's two measures were taken. Firstly, participants rated themselves on a five-point scale ranging from "Very High" to "Very Low". A second measure of performance was a rating using the same five point scale by an expert, based on performance data obtained from the British Eventing website (www.britisheventing.com). On this website a complete history of results is available for every individual that takes part in BE competitions including placings and penalties. A second external person who was knowledgeable in the sport rated $10 \%$ of the data to check reliability which was over $90 \%$.

\subsection{Procedure}

The questionnaire was distributed to individuals at BE events between September and October 2009. The specific events were chosen as they ran different levels of classes to try and obtain participants from the three different rider groups and of different ability levels. Questionnaires were also emailed to professionals, their email addresses were found by searching on the internet to find if they had a website where an email address could be found. The response rate was just over $50 \%$.

\section{Results}

\section{Statistical Analysis}

To test the various hypotheses first correlations were computed followed by step-wise regressions.

The experimenter's ratings significantly correlated with the other knowledgeable person's ratings, $r=0.92$ (18), $p<0.01$, suggesting that the "actual" measure of performance is reliable. The two performance measures —one self-report and "actual" were found to correlate significantly: $r=0.71$ (155), $p<0.001$.

Table 1 shows the correlations between all the major variables. Three variables were significantly correlated with Self-Report ratings which indicated that participants people with high CSE, Conscientiousness and Neuroticism scores rated themselves highly. Only CSE were two significant betas rated to the "actual" performance measure. 
Table 1. Correlations between the major variables.

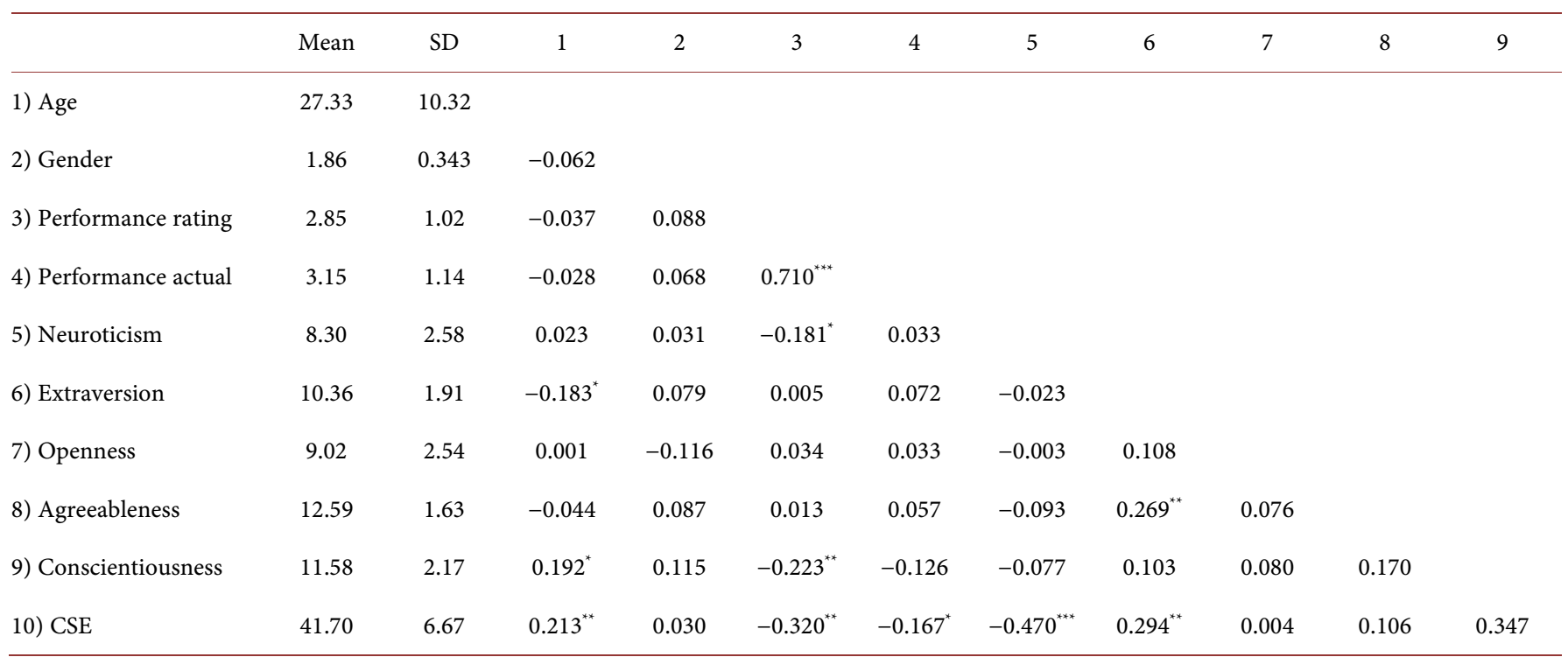

Note. Low scores on the two performance variables indicate high ratings; ${ }^{* * *} p<0.001,{ }^{* *} p<0.01,{ }^{*} p<0.05$.

1) Self-report Performance: First a stepwise regression was computed withy SelfRatings as the criterion variable. First rider type was entered, then age and gender, the CSE and followed by the Big Five. The results from the final step are shown in Table 2. The regression was significant and there were two significant. They indicated that those with higher CSE and Conscientiousness rated themselves more highly.

2) Actual Performance: The same regression analysis was performed on the Actual Performance ratings. This indicated that Professionals with a higher CSE received higher ratings (Table 3 ).

\section{Discussion}

The results show support for the hypothesis that Core Self Evaluations are an important predictor of performance. If individuals have negative and inconsistent views of themselves, they will over-generalise negative implications of failure (Brown \& Dutton, 1995), causing their performance to be lower, as was found. It also may be due to their CSE. Low levels will result in them judging their performance as poor. This hinders their performance and then acts as reinforcement for their initial judgement. Sport is also a great spectator event, and there are often many people surrounding the arena while individuals compete in Eventing. Sanna (1992) found that this could be a hindrance to individuals with low CSE, which could be another contributing factor for the results found.

The results show that out of the Big Five personality traits Conscientiousness is an important predictor of performance as hypothesised. Being hard-working and disciplined is crucial to sport where "practise makes perfect" is key. Another characteristic of Conscientiousness is motivation (Biderman et al., 2008). If individuals have higher levels of motivation, they will be more driven to achieve their goals and will exert greater amounts of effort. 
Table 2. Regression with performance rating as criterion.

\begin{tabular}{ccc}
\hline & Beta & $t$ \\
\hline Rider type & 0.025 & 0.31 \\
Age & 0.088 & 1.05 \\
Gender & 0.109 & 1.36 \\
CSE & -0.312 & $-3.04^{* *}$ \\
Neuroticism & 0.021 & 0.23 \\
Extraversion & 0.106 & 1.21 \\
Openness & 0.045 & 0.57 \\
Agreeableness & 0.032 & 0.39 \\
Conscientiousness & -0.164 & $-1.93^{*}$ \\
& $F(9,145)=2.83, p<0.01$, Adj $^{2}=0.10$ \\
\hline
\end{tabular}

Note: ${ }^{* *} p<0.01 ;{ }^{*} p<0.05$.

Table 3. Regression with actual performance as criterion.

\begin{tabular}{ccc}
\hline & Beta & $t$ \\
\hline Rider type & 0.234 & $2.84^{* *}$ \\
Age & -0.080 & -0.93 \\
Gender & -0.135 & -1.64 \\
CSE & 0.211 & $2.02^{*}$ \\
Neuroticism & 0.061 & 0.67 \\
Extraversion & -0.136 & -1.52 \\
Openness & -0.052 & -0.65 \\
Agreeableness & -0.091 & -1.09 \\
Conscientiousness & 0.108 & 1.26 \\
& $F(9,145)=2.10, p<0.05$, Adj $^{2}=0.06$ \\
\hline
\end{tabular}

Note: ${ }^{*} p<0.01 ;{ }^{*} p<0.05$.

It was also hypothesised that Neuroticism would be a predictor of performance. This was only found when the self-report data was used, however, the trend for low Neuroticism being a facilitator of high performance was seen throughout the data. It is likely that Neuroticism is correlated with CSE as it is one of the factors making it up and this is why it is not found to be a significant predictor on its own. It has already been discussed why it is thought that low Neuroticism is beneficial to performance, however, Mahoney and Avener (1977) believed that it is not the level of anxiety but the ability to control it. Although the trend was for higher performers to be lower on Neuroticism, there may be individuals who have higher levels but have developed efficient coping 
strategies to allow them to perform highly. This would be important to investigate further.

The majority of the results show that Extraversion is not a significant predictor. Eventing is not a very sociable sport, and a lot of time is spent working on your own practising and it could be suggested that those slightly lower on Extraversion are more content with this situation. Also those lower on Extraversion may have better dressage results. This part of the sport does not include a high amount of risk unlike the jumping. Impulsive actions of extraverts that may be advantageous for the cross-country are not necessary for dressage, and rather planned and meticulous actions are required. Therefore, it could be suggested that a more introverted character is required. High dressage performances can often boost overall results.

Neither Agreeableness nor Openness was related to either measures of Eventing performance. This is not surprising as neither seem to play much of a role in sporting success or failure. Agreeableness is more related to interpersonal issues and could play a role in team-sports. Openness is more related to curiosity, imagination and intellect, which usually plays a minor role in competitive sports.

This study had limitations: it used an abbreviated measure of the Big Five and a shortened measure of the virtues which are usually less reliable. Had a longer measure been used, it may have been possible to explore facet level correlates of Eventing.

\section{References}

Bandura, A. (1982). Self-Efficacy Mechanism in Human Agency. American Psychologist, 37, 122147. http://dx.doi.org/10.1037/0003-066X.37.2.122

Barrick, M. R., \& Mount, M. K. (1991). The Big Five Personality Dimensions and Job Performance: A Meta-Analysis. Personnel Psychology, 44, 1-25.

http://dx.doi.org/10.1111/j.1744-6570.1991.tb00688.x

Biderman, M. D., Nguyen, N. T., \& Sebren, J. (2008). Time-on-Task Mediates the Conscientiousness-Performance Relationship. Personality and Individual Differences, 44, 887-897. http://dx.doi.org/10.1016/j.paid.2007.10.022

Bird, E. J. (1970). Personality Structure of Canadian Intercollegiate Women Ice Hockey Players. In G. S. Kenyon (Ed.), Contemporary Psychology of Sport (pp. 43-52). Chicago: Athletic Institute.

British Eventing (2009). About British Eventing. http://www.britisheventing.com/page.asp?section=62\&sectionTitle=About+British+Eventing

Brown, J. D., \& Dutton, K. A. (1995). The Thrill of Victory, the Complexity of Defeat: Self- Esteem and People's Emotional Reactions to Success and Failure. Journal of Personality and Social Psychology, 68, 712-722. http://dx.doi.org/10.1037/0022-3514.68.4.712

Canton, E., \& Mayor, L. (1994). The Sensation of Risk and Motivational Tendencies in Sports: An Empirical Study. Personality and Individual Differences, 16, 777-786.

http://dx.doi.org/10.1016/0191-8869(94)90219-4

Davies, D. (1989). Psychological Factors in Competitive Sport. London: Falmer.

Diehm, R., \& Armatas, S. (2004) Surfing: An Avenue for Socially Acceptable Risk-Taking Satisfying Needs for Sensation Seeking and Experience Seeking. Personality and Individual Differences, 36, 663-677. http://dx.doi.org/10.1016/S0191-8869(03)00124-7 
Dowd, R., \& Innes, J. M. (1981). Sport and Personality: The Effects of Type of Sport and Level of Competition. Perceptual and Motor Skills, 53, 79-89.

http://dx.doi.org/10.2466/pms.1981.53.1.79

Erez, A., \& Judge, T. A. (2001). Relationship of Core Self-Evaluations to Goal Setting, Motivation, and Performance. Journal of Applied Psychology, 86, 1270-1279.

http://dx.doi.org/10.1037/0021-9010.86.6.1270

Eysenck, H. J., Nias, D. K. B., \& Cox, D. N. (1982). Sport and Personality. Advances in Behaviour Research and Therapy, 4, 1-56. http://dx.doi.org/10.1016/0146-6402(82)90004-2

Furnham, A. (1990). Personality and Demographic Determinants of Leisure and Sports Preference and Performance. International Journal of Sport Psychology, 21, 218-236.

Harter, S (1990). Causes, Correlates, and the Functional Role of Global Self-Worth: A Life-Span Perspective. In R. J. Sternberg, \& J. Kolligan, Jr. (Eds.), Competence Considered (pp. 67-97). New Haven, CT: Yale University Press.

Hausenblas, H. A., \& Giacobbi, P. R. (2004). Relationship between Exercise Dependence Symptoms and Personality. Personality and Individual Differences, 36, 1265-1273. http://dx.doi.org/10.1016/S0191-8869(03)00214-9

Judge, T. (2009). Core Self-Evaluations and Work Success. Current Directions in Psychological Science, 18, 58-62. http://dx.doi.org/10.1111/j.1467-8721.2009.01606.x

Judge, T., Erez, A., Bono, J., \& Thorensen, C. (2003). The Core Self-Evaluation Scale. Personnel Psychology, 56, 303-331. http://dx.doi.org/10.1111/j.1744-6570.2003.tb00152.x

Judge, T. A., \& Hurst, C. (2007). The Benefits and Possible Costs of Positive Core Self-Evaluations: A Review and Agenda for Future Research. In D. Nelson, \& C. L. Cooper (Eds.), Positive Organizational Behaviour (pp. 159-174). London: Sage Publications. http://dx.doi.org/10.4135/9781446212752.n12

Kerr, J. H., \& Cox, T. (1991). Arousal and Individual Differences in Sport. Personality and Individual Differences, 12, 1075-1085. http://dx.doi.org/10.1016/0191-8869(91)90037-C

LeUnes, A. D., \& Nation, J. R. (1989). Anxiety, Arousal and Intervention. In A. D. LeUnes, \& J. R. Nation (Eds.), Sport Psychology: An Introduction (pp. 95-120). Chicago, IL: Nelson-Hall.

Mahoney, M. J., \& Avener, M. (1977). Psychology of the Elite Athlete: An Exploratory Study. Cognitive Therapy and Research, 1, 135-141. http://dx.doi.org/10.1007/BF01173634

McManus, I. C., Smithers, E., Partridge, P., Keeling, A., \& Fleming, P. R. (2003). A Levels and Intelligence as Predictors of Medical Careers in UK Doctors: 20 Year Prospective Study. British Medical Journal, 327, 139-142. http://dx.doi.org/10.1136/bmj.327.7407.139

Ogilvie, B. C. (1970). Psychological Consistencies within the Personality of High-Level Competitors. Contemporary Readings in Sport Psychology, 205, 156-162.

Peterson, S. L., Weber, J. C., \& Lonsdale, W. W. (1970). Personality Traits of Women in Team Sports vs. Women in Individual Sports. In W. P. Morgan (Ed.), Contemporary Readings in Sport Psychology (pp. 181-189). Springfield, IL: Thomas.

Salgado, J. F. (1997). The Five Factor Model of Personality and Job Performance in the European Community. Journal of Applied Psychology, 82, 30-43.

http://dx.doi.org/10.1037/0021-9010.82.1.30

Sanna, L. J. (1992). Self-Efficacy Theory. Implications for Social Facilitation and Social Loafing. Journal of Personality and Social Psychology, 62, 774-786. http://dx.doi.org/10.1037/0022-3514.62.5.774

Taylor, J. (1987). Predicting Athletic Performance with Self-Confidence and Somatic and Cognitive Anxiety as a Function of Motor and Physiological Requirements in Six Sports. Journal of 
Personality, 55, 139-153. http://dx.doi.org/10.1111/j.1467-6494.1987.tb00432.x

Vestewig, R. E. (1977). Extraversion and Risk Preference in Portfolio Theory. Journal of Psychology, 97, 237-245. http://dx.doi.org/10.1080/00223980.1977.9923969

Zuckerman, M., Kuhlman, D., Joireman, J., Teta, P., \& Kraft, M. (1993) A Comparison of Three Structural Models for Personality. Journal of Personality and Social Psychology, 65, 757-768.

http://dx.doi.org/10.1037/0022-3514.65.4.757

Submit or recommend next manuscript to SCIRP and we will provide best service for you:

Accepting pre-submission inquiries through Email, Facebook, LinkedIn, Twitter, etc. A wide selection of journals (inclusive of 9 subjects, more than 200 journals)

Providing 24-hour high-quality service

User-friendly online submission system

Fair and swift peer-review system

Efficient typesetting and proofreading procedure

Display of the result of downloads and visits, as well as the number of cited articles Maximum dissemination of your research work

Submit your manuscript at: http://papersubmission.scirp.org/ 